\title{
A Comparative Study on the Preferences of Residents and Tourists in Urban Underground Street Planning
}

\author{
Pei Zhang,2, Jing Liu ${ }^{3, *}$ \\ ${ }^{1}$ School of Tourism, History and Culture, Southwest Minzu University, Chengdu City, China \\ ${ }^{2}$ GSST, Kumamoto University, Kumamoto City, Japan \\ ${ }^{3}$ School of Tourism and Cultural Industry, Sichuan Tourism University, Chengdu City, China \\ *Corresponding author: coocoobar@aliyun.com
}

Received November 11, 2018; Revised March 25, 2019; Accepted June 18, 2019

\begin{abstract}
In urban planning and design, more and more scholars tend to adopt modern sociological research methods to study public opinions and suggestions on urban planning and design. Underground street is an important urban recreation resource. Visitor preference has a very important reference value for measuring the planning effect of underground street because there is no direct interest relationship between visitors and underground street developers or planners. Visitor preference can become a standard to test planner's works, especially for unsuccessful developed underground street. In the current underground street research, no literature has been found to study the visitor preferences. Therefore, this paper takes Diyi Underground Street, an unsuccessful underground street in Chengdu City, China, as an example, adopts the method of questionnaire survey and designs a special scale to investigate two groups of underground street visitors: residents and tourists. It intends to compare and analyze tourists and residents' preferences by using SPSS software, and to explore the key points of underground street planning and transformation in the future. The research divides the questionnaire items into six dimensions: environment, decoration, commercial form, public facilities, traffic and other. The results show that there are not only similarities but also significant differences between residents and tourists in the above six dimensions. Similarity concentrates on the issues of common concern of the two groups, while difference reflects their different recreational needs. Therefore, the planning and design of underground streets in the future should first meet the common needs of residents and tourists, and then, according to the market positioning of underground streets and facing the differences in the number of groups, planning and transformation of key projects should be carried out selectively.
\end{abstract}

Keywords: comparative study, visitor preference, resident, tourist, underground street, urban planning

Cite This Article: Pei Zhang, and Jing Liu, "A Comparative Study on the Preferences of Residents and Tourists in Urban Underground Street Planning." Social and Economic Geography, vol. 4, no. 1 (2019): 8-15. doi: 10.12691/seg-4-1-2.

\section{Introduction}

Urban Underground Street is a public building with the development of underground space, and it is named for its similarity with Ground Shopping Street. Since its emergence, it has been welcomed by various cities. With the rapid development of urban tourism and the continuous expansion of urban scale, underground streets have become the business cards of many cities and an important symbol of urban recreation resources and sustainable development [1].

As a kind of public building, the planning and design of underground street is usually carried out by the planner of the planning agency under the leadership of the government. Under market economy, planners, as a profession, often regard planning as a commodity and sell it to the government or developers. However, planning is not a commodity in the general sense, it has different special attributes from other commodities [2]. Planning is an expression of public policy, and its impact involves every corner of public life. Therefore, when the public interests cannot affect the final planning through specific institutions and mechanisms, if the planning only takes the interests of Party A as the starting point, it will inevitably lead to the deviation of the planning itself [3]. However, if the planning does not take the interests of Party A as the starting point, for example, it will lead to the loss of business for planners. There is no opportunity to be a planner, let alone to talk about the protection of the public interest [4].

Nowadays, planners do face the dilemma of personal and public interests. For this dilemma, planners should not only pay attention to the public and lose the opportunity to serve the public, but also complain about the inadequacy of the planning mechanism so that the public interests cannot be maintained [5]. In the planning and design of underground streets, residents and tourists are two groups of publics who have no direct interest with developers and 
planners. Whether underground street planning can be welcomed by the public eventually, whether the works of planners are recognized by the public, what problems and shortcomings exist, what advantages and disadvantages are there, and so on, the preferences of residents and tourists are a criterion for judging.

In the field of urban planning, underground space is a hot research topic in the field of urban planning and geotechnical engineering. There are some specialized journals, such as Underground Space and Tunnelling and Underground Space Technology in the world. Even in China, there is also a specialized Journal: Chinese Journal of Underground Space and Engineering journal. However, underground space is also a very broad research field. According to the existing research literature, whether in the field of urban planning or in the field of urban tourism, there are few papers on underground streets, although underground streets have been well developed in many countries or regions for nearly 100 years. Especially for the study of underground street visitor preference, no relevant research results have been found.

In fact, preference is a basic concept in the value theory of microeconomics. Preference is both subjective and relative. Visitor preference refers to the psychological tendency of visitors to a certain thing, which is dominated by cognitive factors and has emotional and intentional components. This psychological tendency includes cognitive, emotional and intentional factors. In urban recreation, visitor preference is an important manifestation of visitors' recreational needs. It has a great guiding effect on visitors' recreational behavior and can directly reflect or influence visitors' recreational behavior [6]. Therefore, this paper has to draw on the research methods and achievements of other fields. At present, scholars tend to collect data by means of questionnaires or interviews in all areas of visitor preferences, so as to conduct statistical analysis and processing of data, and propose corresponding solutions [7,8,9]. Preferences have obvious individual differences as well as group characteristics. In urban planning, visitors' preferences are most likely to show significant group differences for planning works that are not recognized by the public. Therefore, this study intends to select Chengdu Diyi Underground Street which has not been successfully developed as a case, and to investigate the preference differences and attitudinal tendencies of the two groups of visitors through the questionnaire, so as to summarize the rules and provide guidance for underground street planning and transformation. The improvement of underground street recreational space is conducive to the promotion of urban tourism image, the improvement of urban functions, and better meet the recreational needs of urban residents and tourists.

\section{Case Study Area}

In this study, we choose Chengdu Diyi Underground Street as the research object. This kind of underground street is very common in the early underground streets of Chinese cities. It is usually reconstructed by civil air defense projects, and most of them are unsuccessful in development. Therefore, the underground streets chosen in this study are of great significance to the development and utilization of underground street recreational resources in modern cities.

Chengdu is located in the middle of Sichuan Province which borders Hubei, Hunan, Guizhou, Yunan, Tibet, Qinghai, Gansu and Shanxi Provinces. It covers an area of 146,000 square kilometers and has a resident population of around 16 million and a floating population of 6 million. Chengdu is the first batch of national historical and cultural cities, the best tourist city in China and one of the best tourist destinations in the world. UNESCO (United Nations Educational Scientific and Culture Organization) gives Chengdu the title of "world food capital" just because of Sichuan Cuisine, Hotpot, and Snacks. Benefiting from Dujiangyan Irrigation Project which was built in 256 B.C., Chengdu is reputed as Tian Fu Zhi Guo in Chinese, which means the land of abundance. Chengdu has two World Heritage Sites and two World Preparatory Heritage Sites. It has the largest number of World Heritage projects in central and Western China. It is also the "most famous Chinese cultural city" with a history of 3200 years. In 2017, Chengdu received 210 million domestic tourists and 3 million 13 thousand inbound tourists.

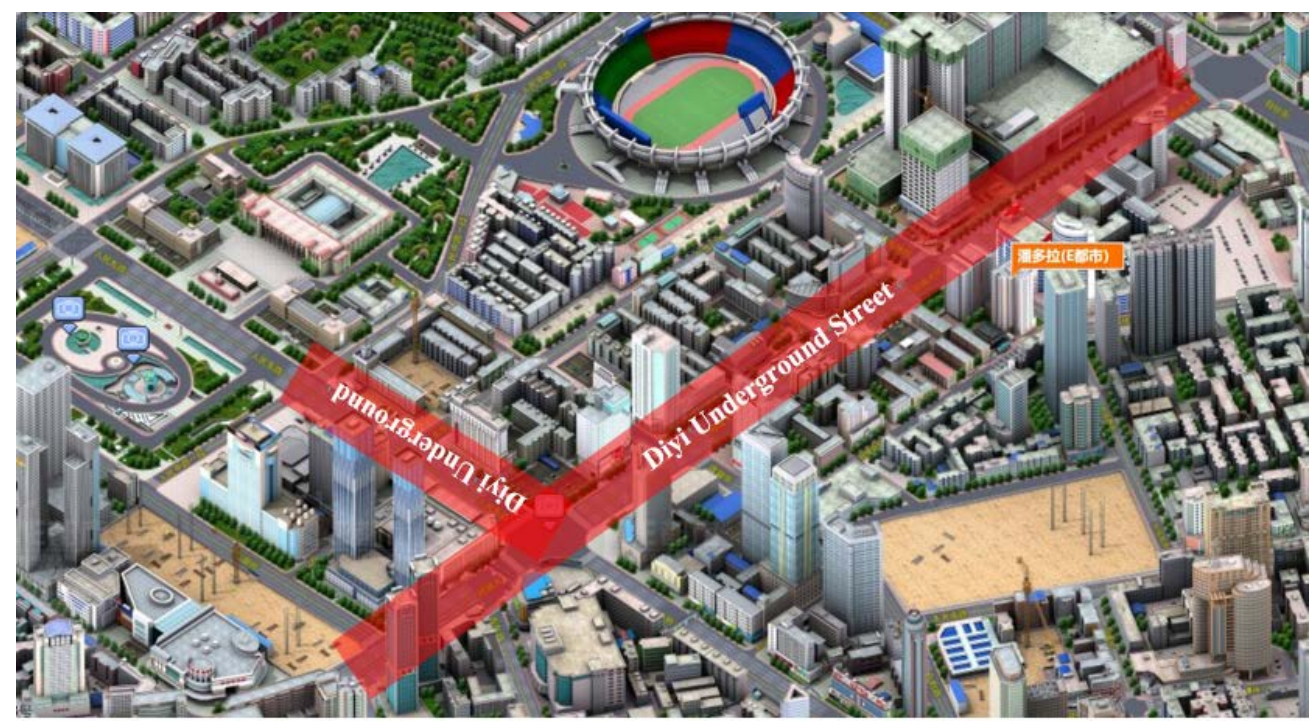

Figure 1. Shape of Diyi Underground Street in the 3D map 
Diyi Underground Street is located in the center of Chengdu, between Chunxi Road, Yanshikou and Luomashi, the three traditional CBDs in Chengdu (Figure 1). The underground street is $\mathrm{T}$ shaped. The ground is Shuncheng Street and people's East Road with huge traffic volume (Figure 1). Because it is very close to the three $\mathrm{CBD}$, there are so many large department stores and office buildings around. There are subway and bus stations near the underground street.

This underground street began with the Yuhe civil air defense project built in September 1971. The total area of Diyi Underground Street is 90,500 square meters. The whole length of Shuncheng Street is 1,216 meters from Fuli Department Store to Yanshikou Business Circle in the north and 425 meters from Tianfu Square, the largest metro transfer station in Chengdu in the west. There are 24 entrances in the whole section. By March 2018, the majority of stores in Diyi Underground Street have closed, and this once-powerful underground street brand will completely withdraw from Chengdu. Not only that, Renhe Group also want to sell all the underground street operation rights, including those located in Harbin, Guangzhou, Wuhan, Dongguan and other cities in China.

\section{Methodology}

This paper makes a comparative study by using the method of questionnaire survey on the preference of residents and tourists after they visited Diyi Underground Street.

\subsection{Questionnaire Design}

According to the research needs, two questionnaires were designed to investigate the residents and tourists. The questionnaire is divided into three parts: the first part is about the demographic characteristics of the respondents, including the basic information of gender, age, occupation, income, education, marital status, etc. The second part is about the influencing factors of underground street users, which are divided into six dimensions: environment, decoration, facilities, format, traffic and other dimensions. The third part is the willingness of the public to stroll the underground street. A total of 58 items were designed in the questionnaire. Except for the first part and the third part, all items were measured by Likert Scale. The scores of each item indicate the respondents' identification with the indicators, and the scores from 5 to 1 indicate that the respondents' identification gradually decreases. Among them, the score of the influencing factors of residents or tourists to go underground is $5=$ =very important, $4=$ =more important, $3=$ important, $2=$ not important, $1=$ not very important.

After the preliminary design of the questionnaire, we got the guidance and suggestions from peer experts. We revised and supplemented the evaluation factors of some items. Then, 50 teachers and students from a university in Chengdu were selected to carry out the pre-test of the questionnaire, which was revised and perfected again, and a formal questionnaire was formed.

\subsection{Data Source}

As mentioned above, the survey respondents of this study are the residents and tourists who visit Diyi Underground Street.

A total of 300 questionnaires were distributed to the public and 294 were recovered, with a recovery rate of 98\%. Among them, 284 valid questionnaires were valid, with an effective rate of 96.60\%; 250 questionnaires were distributed to tourists, and 236 questionnaires were recovered, with a recovery rate of $94.40 \%$. Among them, there were 220 valid questionnaires, with an effective rate of $93.22 \%$.

\subsection{Data Analysis}

The software used in the data analysis is IBM SPSS Amos 22.0. SPSS is a powerful data analysis software that supports research and theory by extending standard multivariate analysis methods (including regression, factor analysis, correlation analysis and variance analysis). With the help of SPSS Amos, attitudinal and behavioral models can be constructed using intuitive graphical or programmed user interfaces. Compared with standard multivariate statistical methods, these models can more accurately reflect complex relationships.

\section{Research Results}

\subsection{Sample Information}

\subsubsection{Sample Information of Residents' Questionnaire}

Table 1. Demographic Characteristics of Residents’ Questionnaire

\begin{tabular}{|c|c|c|c|}
\hline \multicolumn{2}{|l|}{ Category } & Count & Occupation ratio \\
\hline \multirow{2}{*}{ Gender } & Male & 132 & $46.48 \%$ \\
\hline & Female & 152 & $53.52 \%$ \\
\hline \multirow{5}{*}{ Age } & 18-25 years old & 60 & $21.13 \%$ \\
\hline & 26-35 years old & 114 & $40.14 \%$ \\
\hline & 36-45 years old & 50 & $17.61 \%$ \\
\hline & 46-60 years old & 35 & $12.32 \%$ \\
\hline & Over 60 years old & 25 & $8.80 \%$ \\
\hline \multirow{6}{*}{ Occupation } & Civil servant & 76 & $26.76 \%$ \\
\hline & Enterprise staff & 95 & $33.45 \%$ \\
\hline & Freelancer & 26 & $9.15 \%$ \\
\hline & Self-employed & 26 & $9.15 \%$ \\
\hline & Student & 46 & $16.20 \%$ \\
\hline & Others & 15 & $5.28 \%$ \\
\hline \multirow{6}{*}{ Monthly income } & Less than $2000 \mathrm{RMB}$ & 37 & $13.03 \%$ \\
\hline & 2001-3500 RMB & 46 & $16.20 \%$ \\
\hline & 3501-5000 RMB & 72 & $25.35 \%$ \\
\hline & 5001-7500 RMB & 60 & $21.13 \%$ \\
\hline & 7501-10000 RMB & 47 & $16.55 \%$ \\
\hline & More than $10000 \mathrm{RMB}$ & 22 & $7.75 \%$ \\
\hline \multirow{4}{*}{ Education } & High school & 20 & $7.04 \%$ \\
\hline & Undergraduate & 193 & $67.96 \%$ \\
\hline & Master & 31 & $10.92 \%$ \\
\hline & Doctor & 40 & $14.08 \%$ \\
\hline \multirow{2}{*}{ Marital status } & Married & 95 & $33.45 \%$ \\
\hline & Unmarried & 189 & $66.55 \%$ \\
\hline
\end{tabular}


The demographic characteristics of the survey are shown in Table 1. Of all the respondents, men account for $46.48 \%$ and women accounted for $53.52 \%$. The number of people aged 26-35 years was the largest, accounting for $40.14 \%$, followed by $18-25$ years, $36-45$ years and $46-60$ years, accounting for $21.13 \%, 17.61 \%$ and $12.32 \%$, respectively; the number of people over 60 years old was the least, accounting for $8.80 \%$. The largest number of people working in government departments and enterprises were $26.76 \%$ and $33.45 \%$ respectively. Monthly income of 351-5,000 RMB and 5,001-7,000 RMB accounted for the largest proportion, $25.35 \%$ and $21.13 \%$ respectively, followed by 7,501-10,000 RMB, 2,001-3,500 RMB, 2,000 RMB below and more than 10,000 RMB. The majority of undergraduate education accounted for $67.96 \%$. Married people accounted for over $60 \%$ of the survey.

\subsubsection{Sample Information of Tourists' Questionnaire}

Table 2. Demographic Characteristics of Tourists' Questionnaire

\begin{tabular}{|c|c|c|c|}
\hline \multicolumn{2}{|l|}{ Category } & \multirow{2}{*}{$\begin{array}{c}\text { Count } \\
93\end{array}$} & \multirow{2}{*}{$\begin{array}{c}\begin{array}{c}\text { Occupation } \\
\text { ratio }\end{array} \\
42.27 \% \\
\end{array}$} \\
\hline Cold & Male & & \\
\hline Gerluet & Female & 127 & $57.73 \%$ \\
\hline \multirow{5}{*}{ Age } & $18-25$ years old & 14 & $6.36 \%$ \\
\hline & 26-35 years old & 75 & $34.09 \%$ \\
\hline & $36-45$ years old & 78 & $35.45 \%$ \\
\hline & 46-60 years old & 37 & $16.82 \%$ \\
\hline & Over 60 years old & 16 & $7.27 \%$ \\
\hline \multirow{6}{*}{ Occupation } & Civil servant & 51 & $23.18 \%$ \\
\hline & Enterprise staff & 74 & $33.64 \%$ \\
\hline & Freelancer & 11 & $5.00 \%$ \\
\hline & Self-employed & 31 & $14.09 \%$ \\
\hline & Student & 18 & $8.18 \%$ \\
\hline & Others & 35 & $15.91 \%$ \\
\hline \multirow{6}{*}{ Monthly income } & Less than 2000 RMB & 19 & $8.64 \%$ \\
\hline & 2001-3500 RMB & 13 & $5.91 \%$ \\
\hline & 3501-5000 RMB & 79 & $35.91 \%$ \\
\hline & 5001-7500 RMB & 76 & $34.55 \%$ \\
\hline & 7501-10000 RMB & 23 & $10.45 \%$ \\
\hline & More than 10000 RMB & 10 & $4.55 \%$ \\
\hline \multirow{4}{*}{ Education } & High school & 29 & $13.18 \%$ \\
\hline & Undergraduate & 125 & $56.82 \%$ \\
\hline & Master & 45 & $20.45 \%$ \\
\hline & Doctor & 21 & $9.55 \%$ \\
\hline \multirow{2}{*}{ Marital status } & Married & 38 & $17.27 \%$ \\
\hline & Unmarried & 182 & $82.73 \%$ \\
\hline \multirow{5}{*}{ Come from } & $\begin{array}{l}\text { Outside the city or } \\
\text { within the province }\end{array}$ & 94 & $42.73 \%$ \\
\hline & $\begin{array}{l}\text { Beijing, Shanghai, } \\
\text { Guangzhou, Shenzhen }\end{array}$ & 41 & $18.64 \%$ \\
\hline & $\begin{array}{l}\text { Other parts of China } \\
\text { Mainland }\end{array}$ & 57 & $25.91 \%$ \\
\hline & $\begin{array}{l}\text { Taiwan, Macao, } \\
\text { Hongkong }\end{array}$ & 16 & $7.27 \%$ \\
\hline & Foreign country & 12 & $5.45 \%$ \\
\hline \multirow{5}{*}{$\begin{array}{l}\text { Number of } \\
\text { visiting Chengdu }\end{array}$} & 1 & 122 & $55.45 \%$ \\
\hline & 2 & 44 & $20.00 \%$ \\
\hline & 3 & 26 & $11.82 \%$ \\
\hline & 4 & 16 & $7.27 \%$ \\
\hline & More than 5 & 12 & $5.45 \%$ \\
\hline
\end{tabular}

Similarly, the demographic distribution of tourists in this survey is shown in Table 2. Of all the tourists surveyed, the proportion of men and women was $42.27 \%$ and $57.73 \%$ respectively. The number of people aged 26-35 and 36-45 was the largest, accounting for 34.09\% and $35.45 \%$ respectively. Tourists working in enterprises accounted for $33.64 \%$, followed by civil servants and self-employed persons, accounting for $23.18 \%$ and $14.09 \%$ respectively, and tourists from other professions accounted for a certain proportion, accounting for $15.91 \%$. The monthly income level in the 3501--7000 RMB accounted for more than $70 \%$ of the total. The majority of graduates were undergraduates, accounting for 56.82\%. Master and doctoral students also had a certain proportion, $20.45 \%$ and $9.55 \%$ respectively. Married tourists accounted for more than $80 \%$ of the survey. $42.73 \%$ of the tourists lived outside Chengdu and within the province, and $25.91 \%$ of the tourists came from other parts of the country. More than half of the tourists visited Chengdu for the first time.

\subsection{Reliability Analysis and Validity Analysis}

The test of reliability and validity refers to test the reliability and validity of the questionnaire. Specifically, reliability refers to the reliability of questionnaires, that is, the consistency of the results obtained by repeated measurements of the same subject using the same method. Methodologically, the reliability measurement generally adopts the $\boldsymbol{\alpha}$ coefficient method, and the $\boldsymbol{\alpha}$ values of the scale and the dimensions are acceptable above 0.60 . Validity refers to the validity of questionnaires, that is, the degree to which the required measurement can be accurately measured by measuring tools or means. Validity generally adopts structural validity analysis (exploratory factor analysis). Before factor analysis, KMO and Bartlett sphericity tests are needed to test whether the questionnaire is suitable for factor analysis. The closer the $\mathrm{KMO}$ value is to 1 , the more appropriate the questionnaire is for factor analysis. Generally, $\mathrm{KMO}>0.60$ and $\mathrm{P}$ value of Bartlett sphericity test $<0.01$ are suitable for factor analysis. The specific standard of factor analysis is shown in Table 3.

Table 3. Factor analysis standard

\begin{tabular}{|l|c|c|}
\hline Detection category & Range of values & $\begin{array}{c}\text { Suitable situation for } \\
\text { factor analysis }\end{array}$ \\
\hline \multirow{2}{*}{ KMO value } & $>0.8$ & Quite suitable \\
\cline { 2 - 3 } & $0.6 \sim 0.8$ & Suitable \\
\cline { 2 - 3 } & $<0.6$ & Unsuitable \\
\hline $\begin{array}{l}\text { Bartlett sphericity } \\
\text { Check the P value }\end{array}$ & $\leq 0.01$ & Suitable \\
\hline
\end{tabular}

To research conveniently, this paper classifies the questionnaire items into six dimensions, namely, environment, decoration, commercial form, public facilities, traffic and other.

\subsection{Descriptive Analysis}

In order to understand the importance that residents and tourists attach to the environment, decoration, commercial form, public facilities, traffic and other dimensions of underground streets, as well as the general level of willingness to visit again to the underground street and 
recommend the underground street to the surrounding people, this paper makes a descriptive analysis of the following indicators.

\subsubsection{Descriptive Analysis of Resident Questionnaire}

Table 4. Descriptive Analysis of Resident Questionnaire

\begin{tabular}{|l|c|c|c|c|}
\hline Dimension & $\begin{array}{c}\text { Minimum } \\
\text { value }\end{array}$ & $\begin{array}{c}\text { Maximum } \\
\text { value }\end{array}$ & $\begin{array}{c}\text { Average } \\
\text { value }\end{array}$ & $\begin{array}{c}\text { Standard } \\
\text { deviation }\end{array}$ \\
\hline Environment & 1.00 & 4.88 & 2.1162 & .81878 \\
\hline Decoration & 1.00 & 5.00 & 2.2042 & .85998 \\
\hline Commercial form & 1.00 & 5.00 & 2.5927 & .91299 \\
\hline Public facilities & 1.00 & 4.33 & 1.9176 & .59556 \\
\hline Traffic & 1.00 & 4.40 & 2.5592 & .72533 \\
\hline Other & 1.00 & 5.00 & 3.4224 & 1.00088 \\
\hline
\end{tabular}

From Table 4, residents attach the most importance to facilities, environment and decoration in all dimensions of underground street, with an average value of 1.92, 2.12 and 2.20 respectively. Residents pay less attention to commercial form and traffic, with an average value of 2.56 and 2.59 respectively. Relatively speaking, residents pay more attention to commercial promotions, literary and artistic performances and public security. Congruent other class dimensions do not pay much attention, with an average of only 3.42. As for visiting the underground street and recommending the underground street to the people around, the residents still have a more active willingness, with an average of 2.11 and 2.23, respectively. This shows that the residents are willing to support the development and promotion of underground street in their own city.

\subsubsection{Descriptive Analysis of Tourist Questionnaire}

Table 5. Descriptive Analysis of Tourist Questionnaire

\begin{tabular}{|l|c|c|c|c|}
\hline Dimension & $\begin{array}{c}\text { Minimum } \\
\text { value }\end{array}$ & $\begin{array}{c}\text { Maximum } \\
\text { value }\end{array}$ & $\begin{array}{c}\text { Average } \\
\text { value }\end{array}$ & $\begin{array}{c}\text { Standard } \\
\text { deviation }\end{array}$ \\
\hline Environment & 1.00 & 4.00 & 2.4070 & .71882 \\
\hline Decoration & 1.00 & 4.80 & 2.4718 & .90661 \\
\hline Commercial form & 1.00 & 4.27 & 2.2300 & .82250 \\
\hline Public facilities & 1.00 & 3.43 & 1.9322 & .52692 \\
\hline Traffic & 1.00 & 3.60 & 1.8382 & .66730 \\
\hline Other & 1.00 & 5.00 & 3.4408 & .94007 \\
\hline
\end{tabular}

Table 5 shows that, unlike the residents, tourists attach most importance to public facilities, traffic and commercial form, with an average of 1.93, 1.84 and 2.23, respectively, while the requirements for environment and decoration are relatively low, with an average of 2.40 and 2.47 , respectively. Similarly, tourists pay less attention to commercial promotional activities, literary and artistic performances, public security and other dimensions, with an average of only 3.44. Similar to the residents, tourists also have a more active willingness to visit again to the underground street and recommend the underground street to the people around them, with an average of 2.08 .

\subsection{Difference Analysis}

In order to satisfy the recreational consumption demand from residents and tourists as far as possible and improve the experience level of residents and tourists, it is necessary to analyze and compare the importance of each dimension and specific indicators of the main road between residents and tourists. Using t-test, the original hypothesis is that there is no significant difference in the degree of attention paid to a certain dimension or specific indicators between residents and tourists, while the alternative hypothesis is that there is a significant difference in the degree of attention paid to a certain dimension or specific indicators between residents and tourists. Significance level is $1 \%, 5 \%$ and $10 \%$, that is, when $\mathrm{P}$ is lower than the significance level, the original hypothesis can be rejected, and the alternative hypothesis accepted.

\subsubsection{Differences Analysis in Six Dimensions}

Table 6. Differences Analysis in Six Dimensions

\begin{tabular}{|c|c|c|c|c|c|}
\hline Dimension & Grouping & $\begin{array}{c}\text { Average } \\
\text { value }\end{array}$ & $\begin{array}{l}\text { Standard } \\
\text { deviation }\end{array}$ & $\mathrm{T}$ & $\mathrm{P}$ \\
\hline \multirow{2}{*}{ Environment } & Resident & 2.1162 & .81878 & \multirow{2}{*}{-4.168} & \multirow{2}{*}{.000} \\
\hline & Tourist & 2.4070 & .71882 & & \\
\hline \multirow{2}{*}{ Decoration } & Resident & 2.2042 & .85998 & \multirow{2}{*}{-3.383} & \multirow{2}{*}{.001} \\
\hline & Tourist & 2.4718 & .90661 & & \\
\hline \multirow{2}{*}{$\begin{array}{l}\text { Commercial } \\
\text { form }\end{array}$} & Resident & 2.5927 & .91299 & \multirow{2}{*}{4.618} & \multirow{2}{*}{.000} \\
\hline & Tourist & 2.2300 & .82250 & & \\
\hline \multirow{2}{*}{$\begin{array}{l}\text { Public } \\
\text { facilities }\end{array}$} & Resident & 1.9176 & .59556 & \multirow{2}{*}{-.287} & \multirow{2}{*}{.774} \\
\hline & Tourist & 1.9322 & .52692 & & \\
\hline \multirow{2}{*}{ Traffic } & Resident & 2.5592 & .72533 & \multirow{2}{*}{11.458} & \multirow{2}{*}{.000} \\
\hline & Tourist & 1.8382 & .66730 & & \\
\hline \multirow{2}{*}{ Other } & Resident & 3.4224 & 1.00088 & \multirow{2}{*}{-.210} & \multirow{2}{*}{.833} \\
\hline & Tourist & 3.4408 & .94007 & & \\
\hline
\end{tabular}

From Table 6, it can be seen that there are significant differences in environment, decoration, commercial form and traffic dimensions between residents and tourists (t values are -4.168, -3.383, 4.618, 11.458 respectively, corresponding $\mathrm{P}$ values are less than 0.01 , rejecting the original hypothesis and accepting the alternative hypothesis), and there are no significant differences in facilities and other aspects of underground street ( $t$ values corresponding $\mathrm{P}$ values are $-4.168,3.383,4.618$ and 11.458 respectively). The value is greater than 0.10 , accept the original hypothesis. Among them, tourists pay more attention to the underground street environment and decoration than the residents (average 2.12<2.41, $2.20<2.47$ ); the residents pay more attention to the underground street commercial form and traffic than tourists (average 2.59>2.23, 2.56>1.84). Residents focus on public facilities, environment and decoration, while tourists focus on traffic, public facilities and commercial form. For other aspects, both pay less attention.

\subsubsection{Differences Analysis in Environment Dimension}

It analyzes the specific indicators of environment dimension of residents and tourists. From Table 7, there are significant differences in air quality, space, noise, ventilation, humidity and hygiene indicators between residents and tourists ( $\mathrm{t}$ values are $-4.046,-4.257,-5.167$, $-4.947,-1.901,-4.922$, corresponding $\mathrm{P}$ values are less than 0.10 , rejecting the original hypothesis and accepting the alternative hypothesis), but there are no day lighting and temperature indicators. Significant difference ( $\mathrm{t}$ value 
corresponding to $\mathrm{P}$ value greater than 0.10 , accept the original hypothesis). Among them, the public focuses on whether the air quality of underground streets is good, space and day lighting are adequate, while tourists focus on the indicators of space and air quality. Although there are certain differences between the two sides, it is possible to see that the requirements for underground streets are generally high.

Table 7. Differences Analysis in Environment Dimension

\begin{tabular}{|c|c|c|c|c|c|}
\hline Items & Grouping & $\begin{array}{c}\text { Average } \\
\text { value }\end{array}$ & $\begin{array}{l}\text { Standard } \\
\text { deviation }\end{array}$ & $\mathrm{T}$ & $\mathrm{P}$ \\
\hline \multirow{2}{*}{ Air quality } & Resident & 1.8099 & .94314 & \multirow{2}{*}{-4.046} & \multirow{2}{*}{.000} \\
\hline & Tourist & 2.1636 & 1.01160 & & \\
\hline \multirow{2}{*}{ Space } & Resident & 1.6866 & .80876 & \multirow{2}{*}{-4.257} & \multirow{2}{*}{.000} \\
\hline & Tourist & 2.0091 & .88617 & & \\
\hline \multirow{2}{*}{ Day lighting } & Resident & 1.9859 & .98745 & \multirow{2}{*}{.163} & \multirow{2}{*}{.870} \\
\hline & Tourist & 1.9727 & .76997 & & \\
\hline \multirow{2}{*}{ Noise } & Resident & 2.1338 & 1.07150 & \multirow{2}{*}{-5.167} & \multirow{2}{*}{.000} \\
\hline & Tourist & 2.6318 & 1.07520 & & \\
\hline \multirow{2}{*}{ Ventilation } & Resident & 2.0775 & 1.10938 & \multirow{2}{*}{-4.947} & \multirow{2}{*}{.000} \\
\hline & Tourist & 2.5682 & 1.09790 & & \\
\hline \multirow{2}{*}{ Temperature } & Resident & 2.6549 & 1.35577 & \multirow{2}{*}{.203} & \multirow{2}{*}{.839} \\
\hline & Tourist & 2.6318 & 1.14113 & & \\
\hline \multirow{2}{*}{ Humidity } & Resident & 2.4718 & 1.24800 & \multirow{2}{*}{-1.901} & \multirow{2}{*}{.058} \\
\hline & Tourist & 2.6727 & 1.07787 & & \\
\hline \multirow{2}{*}{ Hygiene } & Resident & 2.0915 & 1.10830 & \multirow{2}{*}{-4.922} & \multirow{2}{*}{.000} \\
\hline & Tourist & 2.5864 & 1.13347 & & \\
\hline
\end{tabular}

\subsubsection{Differences Analysis in Decoration Dimension}

Table 8 Differences Analysis in Decoration Dimension

\begin{tabular}{|c|c|c|c|c|c|}
\hline Items & Grouping & $\begin{array}{c}\text { Average } \\
\text { value }\end{array}$ & $\begin{array}{l}\text { Standard } \\
\text { deviation }\end{array}$ & $\mathrm{T}$ & $\mathrm{P}$ \\
\hline \multirow{2}{*}{$\begin{array}{l}\text { Decoration } \\
\text { style }\end{array}$} & Resident & 1.7676 & .91060 & \multirow{2}{*}{-.654} & \multirow{2}{*}{.514} \\
\hline & Tourist & 1.8227 & .97476 & & \\
\hline \multirow{2}{*}{$\begin{array}{l}\text { Decorating } \\
\text { material }\end{array}$} & Resident & 1.8873 & 1.00949 & \multirow{2}{*}{-10.529} & \multirow{2}{*}{.000} \\
\hline & Tourist & 3.0500 & 1.46566 & & \\
\hline \multirow{2}{*}{$\begin{array}{l}\text { Decoration } \\
\text { technology }\end{array}$} & Resident & 2.5352 & 1.30051 & \multirow{2}{*}{-4.428} & \multirow{2}{*}{.000} \\
\hline & Tourist & 3.0864 & 1.48871 & & \\
\hline \multirow{2}{*}{$\begin{array}{l}\text { Lighting } \\
\text { decoration }\end{array}$} & Resident & 2.2183 & 1.18361 & \multirow{2}{*}{-4.289} & \multirow{2}{*}{.000} \\
\hline & Tourist & 2.6909 & 1.28031 & & \\
\hline \multirow{2}{*}{$\begin{array}{l}\text { Floor } \\
\text { covering }\end{array}$} & Resident & 2.2324 & 1.18689 & \multirow{2}{*}{-.598} & \multirow{2}{*}{.550} \\
\hline & Tourist & 2.2955 & 1.15825 & & \\
\hline \multirow{2}{*}{$\begin{array}{l}\text { Ceiling } \\
\text { decoration }\end{array}$} & Resident & 2.4085 & 1.24495 & \multirow{2}{*}{-2.951} & \multirow{2}{*}{.003} \\
\hline & Tourist & 2.7500 & 1.34343 & & \\
\hline \multirow{2}{*}{$\begin{array}{l}\text { Wall } \\
\text { decoration }\end{array}$} & Resident & 2.2606 & 1.21055 & \multirow{2}{*}{.533} & \multirow{2}{*}{.595} \\
\hline & Tourist & 2.2045 & 1.11813 & & \\
\hline \multirow{2}{*}{$\begin{array}{l}\text { Shop } \\
\text { decoration }\end{array}$} & Resident & 2.1831 & 1.15645 & \multirow{2}{*}{-.162} & \multirow{2}{*}{.871} \\
\hline & Tourist & 2.2000 & 1.16494 & & \\
\hline \multirow{2}{*}{$\begin{array}{l}\text { Public } \\
\text { landscape }\end{array}$} & Resident & 2.5282 & 1.34345 & \multirow{2}{*}{.581} & \multirow{2}{*}{.561} \\
\hline & Tourist & 2.4591 & 1.29740 & & \\
\hline \multirow{2}{*}{$\begin{array}{l}\text { Color } \\
\text { matching }\end{array}$} & Resident & 2.0211 & 1.02594 & \multirow{2}{*}{-1.453} & \multirow{2}{*}{.147} \\
\hline & Tourist & 2.1591 & 1.09676 & & \\
\hline
\end{tabular}

It analyzes the specific indicators of decoration dimension of residents and tourists. Table 8 shows that there are significant differences between residents and tourists in decoration materials, decoration technology, lighting decoration and ceiling decoration ( $t$ value corresponding to $\mathrm{P}$ value is less than 0.01 , reject original hypothesis and accept alternative hypothesis), and there are no obvious differences ( $\mathrm{t}$ value corresponding to $\mathrm{P}$ value greater than 0.10 , accept the original hypothesis) in decoration style, floor covering, wall decoration, shop decoration, public landscape and color matching. Among them, the public focuses on the underground street decoration style, decoration materials, color matching and other aspects of the situation, the lighting decoration, floor decoration, shop decoration and other aspects of attention is relatively low. Tourists focus on decoration style, color matching and other indicators. They pay less attention to public landscape, wall decoration, ground pavement and other aspects. They feel indifferent to decoration materials and decoration technology.

\subsubsection{Differences Analysis in Commercial Form Dimension}

Table 9. Differences Analysis in Commercial Form Dimension

\begin{tabular}{|c|c|c|c|c|c|}
\hline Items & Grouping & $\begin{array}{c}\text { Average } \\
\text { value }\end{array}$ & $\begin{array}{l}\text { Standard } \\
\text { deviation }\end{array}$ & $\mathrm{T}$ & $\mathrm{P}$ \\
\hline \multirow{2}{*}{$\begin{array}{l}\text { Brand clothing } \\
\text { store }\end{array}$} & Resident & 2.5141 & 1.29547 & \multirow{2}{*}{2.752} & \multirow{2}{*}{.003} \\
\hline & Tourist & 2.2136 & 1.10408 & & \\
\hline \multirow{2}{*}{$\begin{array}{l}\text { Accessories } \\
\text { store }\end{array}$} & Resident & 2.7254 & 1.26460 & \multirow{2}{*}{4.463} & \multirow{2}{*}{.000} \\
\hline & Tourist & 2.2273 & 1.21376 & & \\
\hline \multirow{2}{*}{$\begin{array}{l}\text { Digital } \\
\text { appliance store }\end{array}$} & Resident & 2.732 & 1.4113 & \multirow{2}{*}{3.485} & \multirow{2}{*}{.001} \\
\hline & Tourist & 2.323 & 1.1628 & & \\
\hline \multirow{2}{*}{ Book store } & Resident & 2.8099 & 1.30740 & \multirow{2}{*}{4.354} & \multirow{2}{*}{.000} \\
\hline & Tourist & 2.3182 & 1.18923 & & \\
\hline \multirow{2}{*}{$\begin{array}{l}\text { Fast food } \\
\text { restaurant }\end{array}$} & Resident & 1.9859 & .97304 & \multirow{2}{*}{3.087} & \multirow{2}{*}{.002} \\
\hline & Tourist & 1.7455 & .70790 & & \\
\hline \multirow{2}{*}{ Snack Bar } & Resident & 2.4859 & 1.23972 & \multirow{2}{*}{5.377} & \multirow{2}{*}{.000} \\
\hline & Tourist & 1.9318 & 1.01580 & & \\
\hline \multirow{2}{*}{$\begin{array}{l}\text { Coffee shop/ } \\
\text { Teahouse }\end{array}$} & Resident & 1.9155 & .91314 & \multirow{2}{*}{$\begin{array}{c}- \\
1.222\end{array}$} & \multirow{2}{*}{.222} \\
\hline & Tourist & 2.0227 & 1.05312 & & \\
\hline \multirow{2}{*}{ Bar } & Resident & 2.0317 & 1.03766 & \multirow{2}{*}{$\begin{array}{c}- \\
1.289 \\
\end{array}$} & \multirow{2}{*}{.198} \\
\hline & Tourist & 2.1545 & 1.09115 & & \\
\hline \multirow{2}{*}{ Drugstore } & Resident & 3.0352 & 1.47254 & \multirow{2}{*}{6.287} & \multirow{2}{*}{.000} \\
\hline & Tourist & 2.2727 & 1.17360 & & \\
\hline \multirow{2}{*}{$\begin{array}{l}\text { Convenient } \\
\text { store }\end{array}$} & Resident & 2.6444 & 1.27088 & \multirow{2}{*}{6.580} & \multirow{2}{*}{.000} \\
\hline & Tourist & 1.9818 & .89117 & & \\
\hline Household & Resident & 2.8028 & 1.36715 & & \\
\hline goods store & Tourist & 2.1955 & 1.17546 & 5.254 & .000 \\
\hline Mother and & Resident & 2.7465 & 1.29929 & 67 & 003 \\
\hline baby shop & Tourist & 2.4045 & 1.26237 & $2.96 /$ & .003 \\
\hline Children's & Resident & 2.7254 & 1.28126 & & 000 \\
\hline playground & Tourist & 2.0409 & .82935 & 84 & .000 \\
\hline & Resident & 3.0352 & 1.37320 & & \\
\hline Beauty & Tourist & 2.3955 & 1.21744 & 5.448 & .000 \\
\hline Ballroom / & Resident & 2.7606 & 1.29107 & 165 & 869 \\
\hline Kara OK hall & Tourist & 2.7409 & 1.37198 & .105 & .009 \\
\hline & Resident & 2.5000 & 1.32254 & & \\
\hline UII & Tourist & 2.5045 & 1.31898 & & 900 \\
\hline
\end{tabular}

It analyzes the specific indicators of the dimensions of residents and tourists. From Table 9, it can be seen that there are significant differences in the demand for brand clothing stores, accessories stores, digital electronics stores, bookstores, fast food restaurants, snack stores, pharmacies, small supermarkets, household goods stores, mother and baby shops, children's playground, beauty salons, Ballroom / Kara OK halls, cinemas and so on between residents and tourists ( $\mathrm{t}$ value corresponding to $\mathrm{P}$ 
value is less than 0.01). However, there was no significant difference in demand for coffee shops/ teahouses and bars ( $\mathrm{p}$ value of $\mathrm{T}$ value was greater than 0.10 , accept the original hypothesis). Among them, the public focuses on whether underground streets have coffee shop/ teahouse, bars, fast food restaurants and other formats, while tourists focus on whether underground streets have fast food restaurants, snack shops, convenient stores and other formats. Visibly, the public attaches great importance to experience in depth in the underground street, preferring to "sit down" to enjoy life experience, so the demand for "slow life" mode is higher; tourists attach importance to experience local cuisine, customs and other local culture in the underground street, while there are certain requirements for the convenience of shopping in the underground street.

\subsubsection{Differences Analysis in Public Facilities Dimension}

Table 10. Differences Analysis in Public Facilities Dimension

\begin{tabular}{|c|c|c|c|c|c|}
\hline Items & Grouping & $\begin{array}{c}\text { Average } \\
\text { value }\end{array}$ & $\begin{array}{l}\text { Standard } \\
\text { deviation }\end{array}$ & $\mathrm{T}$ & $\mathrm{P}$ \\
\hline \multirow{2}{*}{ Toilet } & Resident & 1.7817 & .71448 & \multirow{2}{*}{-6.501} & \multirow{2}{*}{.000} \\
\hline & Tourist & 2.2909 & 1.04112 & & \\
\hline \multirow{2}{*}{ Bank ATM } & Resident & 2.106 & 1.0480 & \multirow{2}{*}{2.446} & \multirow{2}{*}{.015} \\
\hline & Tourist & 1.895 & .8237 & & \\
\hline \multirow{2}{*}{$\begin{array}{l}\text { Rest table and } \\
\text { chair }\end{array}$} & Resident & 1.6268 & .72423 & \multirow{2}{*}{-2.085} & \multirow{2}{*}{.038} \\
\hline & Tourist & 1.7591 & .68324 & & \\
\hline \multirow{2}{*}{$\begin{array}{l}\text { Communication } \\
\text { facilities }\end{array}$} & Resident & 1.9437 & .83877 & \multirow{2}{*}{-1.162} & \multirow{2}{*}{.246} \\
\hline & Tourist & 2.0409 & 1.03948 & & \\
\hline \multirow{2}{*}{ Elevator } & Resident & 1.9859 & .89747 & \multirow{2}{*}{-.705} & \multirow{2}{*}{.481} \\
\hline & Tourist & 2.0409 & .82935 & & \\
\hline \multirow{2}{*}{ Guide sign } & Resident & 2.0634 & .85908 & \multirow{2}{*}{6.065} & \multirow{2}{*}{.000} \\
\hline & Tourist & 1.6227 & .73927 & & \\
\hline
\end{tabular}

It analyzes the specific indicators of the facilities dimensions of the residents and tourists. Table 10 shows that there are significant differences in public toilets, bank ATMs, rest tables and chairs, and guide signs between residents and tourists (the corresponding $\mathrm{P}$ value of $\mathrm{T}$ value is less than 0.01 , rejecting the original hypothesis and accepting the alternative hypothesis), but there is no significant difference in the demand for communication facilities and elevators (the $\mathrm{P}$ value of $\mathrm{T}$ value is greater than 0.10 , accepting the original hypothesis). Among them, the public focuses on whether the underground street has rest seats, public toilets, elevators and other ancillary facilities. Tourists focus on whether the underground street has guidance signs, rest seats, bank ATMs and other ancillary facilities. It can be seen that the residents prefer to have some recreational places when they have leisure consumption in underground streets, while tourists prefer to have some facilities convenient for sightseeing in underground streets.

\subsubsection{Differences Analysis in Traffic Dimension}

The specific indicators of the traffic dimension of the residents and tourists are analyzed here. From Table 11, there are significant differences between residents and tourists in the demand for public traffic, department store, office building and parking building (t value corresponding to $\mathrm{P}$ value is less than 0.01 , rejecting the original hypothesis and accepting the alternative hypothesis). Among them, the residents hope that underground street can be matched with subway, public transport (average 2.09, 2.34), in order to facilitate access to and leave the underground street; tourists have a stronger demand for subway and public transport (average 1.60, 1.64), and also need to be able to go to department stores and other public transport spots.

Table 11. Differences Analysis in Traffic Dimension

\begin{tabular}{|c|c|c|c|c|c|}
\hline Items & Grouping & $\begin{array}{c}\text { Average } \\
\text { value }\end{array}$ & $\begin{array}{l}\text { Standard } \\
\text { deviation }\end{array}$ & $\mathrm{T}$ & $\mathrm{P}$ \\
\hline \multirow{2}{*}{$\begin{array}{l}\text { Connecting with } \\
\text { subway }\end{array}$} & Resident & 2.0915 & .84824 & \multirow{2}{*}{6.850} & \multirow{2}{*}{.000} \\
\hline & Tourist & 1.6000 & .73030 & & \\
\hline \multirow{2}{*}{$\begin{array}{l}\text { Connecting with } \\
\text { bus stop }\end{array}$} & Resident & 2.3380 & 1.10180 & \multirow{2}{*}{7.855} & \multirow{2}{*}{.000} \\
\hline & Tourist & 1.6409 & .81826 & & \\
\hline \multirow{2}{*}{$\begin{array}{l}\text { Connecting with } \\
\text { department sore }\end{array}$} & Resident & 2.6479 & 1.17811 & \multirow{2}{*}{8.232} & \multirow{2}{*}{.000} \\
\hline & Tourist & 1.8591 & .90314 & & \\
\hline \multirow{2}{*}{$\begin{array}{l}\text { Connecting with } \\
\text { office building }\end{array}$} & Resident & 3.0915 & 1.08250 & \multirow{2}{*}{11.116} & \multirow{2}{*}{.000} \\
\hline & Tourist & 2.0455 & 1.00124 & & \\
\hline \multirow{2}{*}{$\begin{array}{l}\text { Connecting with } \\
\text { parking lots }\end{array}$} & Resident & 2.6268 & 1.08709 & \multirow{2}{*}{5.991} & \multirow{2}{*}{.000} \\
\hline & Tourist & 2.0455 & 1.07173 & & \\
\hline
\end{tabular}

\section{Discussion and Conclusion}

\subsection{Discussion}

Visitor preference is a true reflection of individual perception and recreational needs. Under the background of space-time compression, accompanied by the normalization and activation of recreational activities, at least within the scope of urban tourism, self-help tourists and self-selected tourists have fully entered the public living space of the residents of the destination, and the destination has increasingly become the living space shared by both foreign tourists and residents. For cities with shared living space, people's perception is a comprehensive experience formed by sensory stimulation such as vision, hearing, touch, smell and taste. The percentages of knowledge absorbed by five sensory organs of a healthy person are as follows: visual perception, auditory perception, olfactory perception, tactile perception and taste perception accounted for $83 \%, 11 \%, 3.5 \%, 1 \%$ and $1 \%$ respectively [10]. Of course, people's observation and perception of the city is not only a single perception, but also a comprehensive resonance from all perceptions. At the same time, it is a comprehensive perception impression that integrates multiple experiences. Therefore, in this study, due to the content of sensory stimulation and the commonality of living environment, on the one hand, the respondents (that is, recreationists, including residents and tourists) show the same perception results, on the other hand, different recreational experiences will appear. As far as the course of recreational experience is concerned, Clawson and Knetsch put forward the essence of multistage recreational experience [11], that is, the complete recreational experience includes anticipate phase, travel to the site, on-site activities, return travel and recollection phase. There are five stages, and the psychological experience and feeling of each stage are not the same. Among them, the recreational experience of recreation participants in the stage of on-site activities is complex 
and changeable [12]. Different moods and physical conditions will affect the main body of recreation during on-site activities. Therefore, the psychological anxiety and pressure of recreation participants in the face of recreational activities will also lead to different recreational experiences [13]. It is the trend and requirement of the humanized development of underground streets to create a comprehensive new place combining culture, commerce, recreation and sightseeing by means of planning and design in the future.

\subsection{Conclusion}

This paper discusses the general situation of the resident questionnaire and tourist questionnaire and the overall level of each dimension based on guaranteeing the reliability and validity of the two questionnaires, focusing on the dimension of the environment, decoration, commercial form, public facilities and traffic of case study underground street. The results of the above-mentioned survey for residents and tourists reflect two problems: One is the difference of recreation preferences between tourists and residents, which is a true reflection of their individual perception and recreational needs; the other is the deficiency of existing planning and design.

The results show that the preferences of residents and tourists to the various dimensions of the underground street are different. Residents pay more attention to the public facilities, environment and decoration of the underground street. Tourists pay more attention to traffic, public facilities and commercial form, and these three dimensions promote it again.

Specifically, in terms of environment, the residents hope that the air quality of the underground street will be improved, and that there will be more space and better lighting conditions. Tourists hope to expand the space of the underground street and improve air quality. In terms of decoration, both the residents and tourists hope that the underground street pay attention to color matching and adopt better decoration materials. Material upgrade decoration grade and improve to a more visual decoration style; in terms of commercial form and public facilities, the residents hope that the underground street has "slow rhythm" commercial form such as coffee shop, tea house, bar, fast food restaurant, and set up some rest chairs, public toilets, elevators and other supporting facilities to experience life "slowly" down in the underground street. Tourists hope that the underground street will have "convenience" commercial forms such as fast food restaurants, snack shops and supermarkets, and set up supporting facilities such as guide signs, rest seats, bank
ATM machines to meet their basic tourism needs. In terms of traffic, both residents and tourists hope that the underground street can be connected with public transport such as subway stations and bus stops. In order to facilitate the arrival and departure of the underground street, tourists also hope that the underground street will be connected with department stores, office buildings and parking lots to facilitate access to other tourist attractions.

\section{Acknowledgements}

This study is funding by the research project of Sichuan Tourism Youth Expert (No. SCTYETP2017L28) and research project of Sichuan Education Department (No. 17SB0354).

\section{References}

[1] Zhang, P. (2018). Japanese ways of developing urban underground recreation space. World Journal of Engineering and Technology, 6 , 504-517.

[2] Nigel Taylor. (1998). Urban Planning Theory Since 1945. New York: SAGE Publication.

[3] Wu, Z. Q. (2014). Effect of third-party participation in urban planning: a case study on Enning Road in Guangzhou. Urban Planning, 38(2), 62-75.

[4] Liu, J. Y. (2007). Discussion on rising and development experience of Japanese underground town. International Urban Planning, 22(6), 47-52.

[5] Jacques Besner. (2017). Cities think underground - underground space (also) for people. Procedia Engineering, 209, 49-55.

[6] Cranenburgh, S. V., Chorus, C. G., \& Wee, B. (2014). Vacation behaviour under high travel cost conditions: A stated preference of revealed preference approach. Tourism Management, 2014, 43, 105-118.

[7] Aslak Fyhri, Jens Kristian Steen, Jacobsen,Hans (2009). Tommervik. Tourists' landscape perceptions and preferences in a Scandinavian coastal region. Landscape and Urban Planning, (91):202-211.

[8] Xiang X.W., Zhen L.F., Zhang J.H. (2016). How smart is your tourist attraction? Measuring tourist preferences of smart tourism attractions via a FCEM-AHP and IPA approach. Tourism Management, (54):309-320.

[9] Daud Mohamad, Rozana Mohd Jamil. (2012). A preference analysis model for selecting tourist destinations based on motivational factors: A case study in Kedah, Malaysia. Procedia-Social and Behavioral Sciences, (65):20-25.

[10] Sun, Y. Y., Piao, Y. J., Zhu, W. Q. (2010). Research on landscape five senses design. Modern Landscape Architecture. (12): 37-40.

[11] Clawson M, Knetsch J. L. (1996). Economics of Outdoor Recreation. Baltimore: The Johns Hopkins Press, p.328.

[12] Ittelson W. H. (1978). Environmental perception and urban experience. Environment and Behavior, 10(2), 193-213.

[13] Hull R. B. IV., Steward W. P., Yi Y. K. (1992). Experience pattern: Capturing the dynamic nature of a recreation experience. Journal of Leisure Research, 24(3), 240-252. 